\title{
Preconditioning Deep Convection with Cumulus Congestus
}

\author{
CATHy HoHENEGger AND BJORn STEVEnS \\ Max Planck Institute for Meteorology, Hamburg, Germany
}

(Manuscript received 16 March 2012, in final form 29 June 2012)

\begin{abstract}
Recent studies have pushed forward the idea that congestus clouds, through their moistening of the atmosphere, could promote deep convection. On the other hand, older studies have tended to relate convective initiation to the large-scale forcing. These two views are here contrasted by performing a time-scale analysis. The analysis combines ship observations, large-eddy simulations, and 1 month of brightness temperature measurements with a focus on the tropical Atlantic and adjacent land areas.

The time-scale analysis suggests that previous work may have overstated the importance of congestus moistening in the preconditioning of deep convection. It is found that cumuli congestus transition very rapidly to deep convection, in $2 \mathrm{~h}$ over land and $4 \mathrm{~h}$ over ocean. This is much faster than the time needed $(10 \mathrm{~h}$ and longer) by congestus clouds to sufficiently moisten the atmosphere. Moreover, the majority of congestus clouds seem unable to grow into cumulonimbus and the probability of transition does not increase with increasing congestus lifetime (i.e., more moistening). Finally, the presence of cumuli congestus over a given region generally does not enhance the likelihood for deep convection development, either with respect to other regions or to clear-sky conditions. Hence, the results do not support the view of an atmosphere slowly deepening by local moistening, but rather, they may be interpreted as reminiscent of an atmosphere marked by violent and sudden outbursts of convection forced by dynamical effects. This also implies that moisture convergence is more important than local surface fluxes to trigger deep convection over a certain region.
\end{abstract}

\section{Introduction}

Cumuli congestus are defined as "strongly sprouting cumuli with generally sharp outlines and often great vertical extent" (WMO 1956, p. 40). In contrast to shallow (trade wind) cumuli, they populate the midlevels of the atmosphere. Their sharp contour distinguishes them from the cumulonimbus where the production of numerous ice crystals leads to a fibrous texture and to anvil formation. In observations, congestus clouds can be identified by a peak in reflectivity or by a layer of enhanced detrainment/divergence typically situated around $500 \mathrm{hPa}$ in the tropics (e.g., Johnson et al. 1999; Takayabu et al. 2006; Schumacher et al. 2007). Such layers are associated with marked changes in the environmental conditions, either in thermal stability (e.g., Johnson et al. 1999) or relative humidity (e.g., Takemi et al. 2004; Jensen and Del Genio 2006).

Corresponding author address: Cathy Hohenegger, Max Planck Institute for Meteorology, Bundesstrasse 53, 20146 Hamburg, Germany.

E-mail: cathy.hohenegger@zmaw.de
Cumuli congestus are abundant in the tropics. They constitute the third dominant cloud population beside shallow cumulus and cumulonimbus (Johnson et al. 1999; Masunaga et al. 2005). From a thermodynamic point of view, congestus clouds warm and moisten the atmospheric column (e.g., Schumacher et al. 2007; Takayabu et al. 2010). Most importantly, they are thought to produce between $25 \%$ and $45 \%$ of the total rainfall over the tropics (Houze and Cheng 1977; Johnson et al. 1999; Lau and Wu 2003; Petty 1999; Stephens et al. 2002). This makes cumulus congestus an important cloud category per se.

Beyond this, the idea has emerged that cumuli congestus are necessary for initiating deep convection. Many studies have documented that the presence of layers of dry air, through entrainment of environmental air into the cloud, can effectively limit the depth of convection (Brown and Zhang 1997; Parsons et al. 2000; Redelsperger et al. 2002; Derbyshire et al. 2004; Takayabu et al. 2010). The logical consequence is that, if a process can moisten the atmosphere, it will force the development of deeper clouds. Moistening by cumulus congestus constitutes such a process. 
The relationship between moisture, cumulus congestus, and deep convection is ambiguous. The previously mentioned observational studies have demonstrated that a link exists between dry air and suppressed convection. However, none of them provided direct evidence that moistening by cumulus congestus enhances the likelihood for deep convection initiation. Likewise, our day-to-day experience of the convective diurnal cycle teaches us that shallow cumuli grow into congestus that will grow into cumulonimbi. Although visually suggestive, this progression does not prove any causal connection between the three cloud categories.

Several studies have also reported the concurrent occurrence of cumulus congestus and moistening in advance of the active phase of the Madden-Julian oscillation (MJO) (e.g., Blade and Hartmann 1993; Benedict and Randall 2007). Further studies (e.g., Slingo et al. 2003) have attributed the failure of current global climate models (GCMs) to capture the MJO to a misrepresentation of the congestus population (which tends to be absent in such GCMs). Other studies have emphasized different mechanisms (e.g., Jones and Weare 1996; Zhang 2005); the unraveling of the mechanisms controlling the dynamic of the MJO is the objective of the Dynamics of the Madden-Julian Oscillation (DYNAMO) field campaign, which took place over the Indian Ocean from late 2011 through early 2012.

Although the effects of congestus clouds are hard to disentangle in observations, numerical experiments with cloud-resolving models can help guide our thinking. Kuang and Bretherton (2006) studied an idealized transition from shallow to deep convection by means of cloud-resolving simulations and investigated the statistics of the deepening cloud layer. Building on this, Waite and Khouider (2010) specifically explored the role of congestus clouds. The simulations demonstrated how detrainment of water vapor from congestus clouds moistens the atmospheric column with time and promotes the transition to deep convection. However, the simulations did not incorporate any large-scale forcing. Yet it is known both from simulations and observations that forced ascent-as, for example, associated with largescale convergence (e.g., Krueger 1988; Xu et al. 1992; Mapes and Houze 1995; Yuter et al. 2005; Masunaga and Kummerow 2006; Back and Bretherton 2005), mesoscale circulations (e.g., Pielke 2001), or cold pools (e.g., Tompkins 2001)—can promote the development of deep convection.

The question thus arises whether congestus moistening is a generally important process for the transition to deep convection given the wealth of forcing that the atmosphere may experience. The present study is devoted to this question, which is approached through an investigation of the time scales that characterize the transition from congestus to cumulonimbus on the one hand and processes thought to be driving this transition on the other hand. If one of these processes stands out as a very-slow-acting process, its contribution to the initiation of deep convective cells can be ruled out. The two main investigated processes are cumulus congestus moistening and moistening resulting from forced ascent. In the first case, the atmosphere is viewed as an otherwise quiescent fluid in which cumuli congestus develop randomly in response to stationary and homogeneous surface fluxes. The congestus clouds gradually moisten the troposphere. The moistening mainly results from clouds transporting evaporated water from the surface higher up in the atmosphere. As time goes on the congestus clouds progressively deepen and eventually transition to deep convection. In the second case, the atmosphere is moistened by the imposed vertical motion, promoting the development of deep convection. Ascent implies convergence of moisture in the atmospheric column. The present study identifies characteristic time scales for these two processes and explores to what extent a difference between the respective time scales can be used to distinguish which process is dominant in nature. Whereas the first case only relies on moisture supplied by the surface fluxes, the second case benefits from moisture advected by the flow in the region of interest. In this sense, the study also indirectly assesses the importance of surface fluxes versus moisture convergence for the development of deep convection. Also, both congestus and forced ascent, beyond moistening the atmospheric column, destabilize the atmosphere, which can further help the transition.

To estimate the different time scales, this study uses high-resolution observations from geostationary satellites, ship observations, and large-eddy simulations (LES). The focus is set on the tropical region $\left(30^{\circ} \mathrm{S}-30^{\circ} \mathrm{N}\right)$ between South America and Africa (from $70^{\circ} \mathrm{W}$ to $30^{\circ} \mathrm{E}$ ), where both ship measurements and high-frequency satellite observations are present. The use of data from geostationary satellites and especially of brightness temperature measurements, despite being an indirect measure of convective activity, is a widely applied approach to infer features of tropical convection (e.g., Hendon and Woodberry 1993; Machado et al. 1993; Raymond et al. 2003; Schroeder et al. 2009).

The outline of the paper is as follows. Section 2 presents the method and describes the observational datasets, large-eddy simulations, and metrics (time scales). The following three sections deal with the time-scale analysis: section 3 estimates the time scales resulting from moistening by congestus clouds and from some form of imposed ascent using a bulk approach, section 4 repeats the 
analysis based on LES, and section 5 deals with observed transition times as derived from brightness temperature measurements. Sections 6 and 7 discuss and summarize the obtained results.

\section{Method}

To disentangle the effects of congestus moistening from forced ascent in the transition to deep convection, measurements collected over the tropics as well as LES are explored. Satellite observations are used to isolate congestus from cumulonimbus clouds and thus to estimate characteristic transition times. Atmospheric measurements taken on ship expeditions, on the other hand, are used to provide some information on the environmental conditions in which convection develops and, likewise, on the effects of convection on its environment. This allows characterization of the typical time scales associated with pure congestus moistening and moistening resulting from forced ascent. Finally, LES allows estimation of transition time scales under different moistening scenarios-that is, only congestus versus imposed ascent. Sections $2 \mathrm{a}$ and $2 \mathrm{~b}$ describe the employed observational datasets and the LES model. Section $2 \mathrm{c}$ defines the relevant time scales and explains in more detail the associated computation methodology.

\section{a. Observations}

As a first observational source, brightness temperature measurements from the Meteosat Second Generation (MSG) satellite (Schnetz et al. 2002) have been extracted from the European Organisation for the Exploitation of Meteorological Satellites (EUMETSAT) archive. The data are inferred from radiances measured in the infrared at $10.8 \mu \mathrm{m}$. The latter channel facilitates a distinction between congestus and cumulonimbus clouds on the basis of a much colder cloud-top temperature for the cumulonimbi. The data are also available at high spatiotemporal resolution, which is crucial for the questions posed in this study. Brightness temperature is provided each $15 \mathrm{~min}$ on a grid with a $3-\mathrm{km}$ resolution at nadir. This is interpolated to a regular latitude-longitude grid with $0.1^{\circ}$, or roughly $10-\mathrm{km}$ resolution. Because of the amount of data involved, the analysis is limited to the tropical region between $30^{\circ} \mathrm{S}$ and $30^{\circ} \mathrm{N}$ and between $70^{\circ} \mathrm{W}$ and $30^{\circ} \mathrm{E}$ and to one particular month. The chosen month is May 2010 to match the season with available ship observations (see below).

The second dataset comprises vertical profiles of temperature and moisture taken every day at noon on board the German research vessel Polarstern. Polarstern crosses the Atlantic Ocean 2 times per year, in late fall and spring, on its way from its home port in Bremerhaven to
Antarctica and back. For this study observations collected during the spring 2011 transect (20 April-20 May 2011) are analyzed.

The last dataset is made of large-scale vertical velocities derived from a network of soundings deployed during the Global Atmospheric Research Program Atlantic Tropical Experiment (GATE; Houze and Betts 1981). GATE took place over the tropical Atlantic with the objective to improve basic understanding of tropical convection. The data are available on a 3-hourly basis for the time period 30 August-18 September 1974, and on a $1^{\circ} \times 1^{\circ}$ resolution grid with 19 vertical levels. The GATE domain covers the area $4^{\circ}-14^{\circ} \mathrm{N}, 19^{\circ}-28^{\circ} \mathrm{W}$. Despite the different observational period, the GATE dataset is retained because it represents the only dataset of observed large-scale vertical velocity for the tropical Atlantic.

Diagnosing vertical velocity from a network of soundings is a common way to infer vertical motion from field experiments, although it is subject to uncertainties. The contribution of the large-scale flow to the derived vertical velocities is difficult to isolate from the contribution of the convective signal itself. Large-scale convergence may promote deep convection, which, in turn, will reinforce convergence in the lower layers and divergence in the upper ones. The stronger the diagnosed vertical velocities appear, the more the convection feeds back on the synoptic scale. Second, sampling errors can bias estimates of large-scale vertical velocity by up to $40 \mathrm{hPa}$ day $^{-1}$ (e.g., Mapes et al. 2003). To take such effects into account, a range of large-scale vertical velocities rather than one single realization is retained from the GATE dataset. Figure 1 shows the relative frequency of the large-scale vertical velocities derived from GATE data, vertically averaged below $10 \mathrm{~km}$. Averaged values are sufficient for the type of computation and analysis that will be performed. Negative velocities imply subsidence, which hampers convective development, whereas positive velocities promote deep convection. The distribution peaks at $0.01 \mathrm{~m} \mathrm{~s}^{-1}$ and the maximum observed velocities lie around $0.05 \mathrm{~m} \mathrm{~s}^{-1}$. Hence, the latter two values will be employed to get a rough idea of possible vertical motions that the atmosphere may experience.

\section{b. LES model}

The simulations are performed with the University of California, Los Angeles (UCLA) LES (Stevens et al. 2005). The UCLA-LES has been widely applied for the study of boundary layers and boundary layer clouds and extensively evaluated through several intercomparison exercises under the Global Energy and Water Cycle Experiment (GEWEX) Cloud System Study (GCSS) framework (e.g., Brown et al. 2002; Siebesma et al. 2003; 


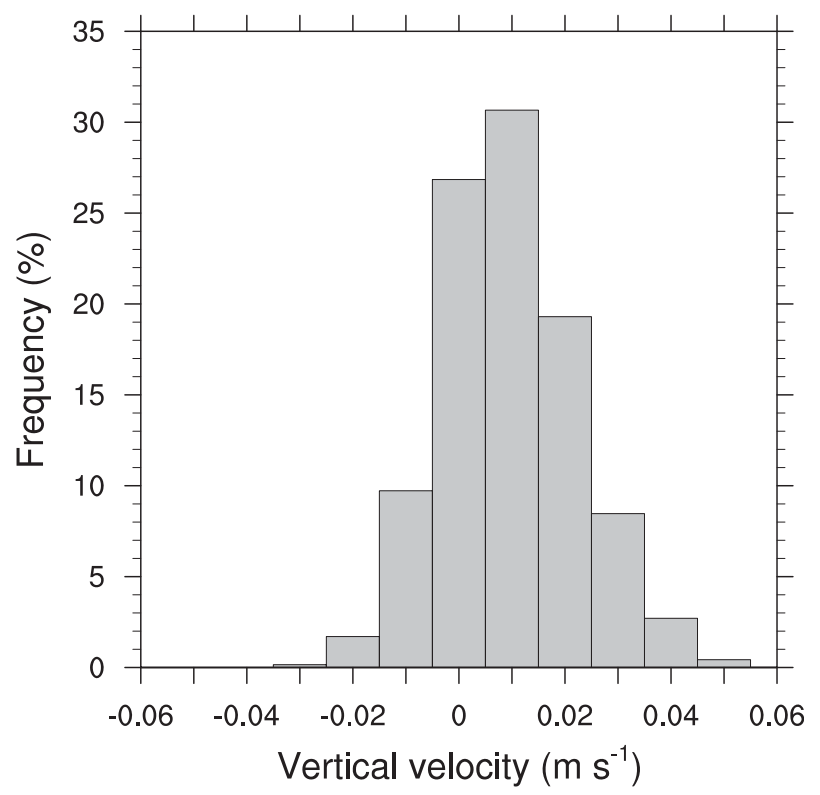

FIG. 1. Frequency distribution (\%) of large-scale vertical velocity $\left(\mathrm{m} \mathrm{s}^{-1}\right)$. The data are from GATE and have been vertically averaged below $10 \mathrm{~km}$.

Stevens et al. 2005; Ackerman et al. 2009). The UCLALES solves the three-dimensional anelastic equations with centered differencing in space for momentum variables and upwinding for scalar variables. The time marching employs a third-order Runge-Kutta scheme. Parameterizations include a Smagorinsky-type scheme to represent subgrid-scale turbulence. As a recent addition, the two-moment ice microphysics scheme of Seifert and Beheng (2006) was implemented in the model to allow the simulation of deep convection.

The simulations performed with the UCLA-LES cover a domain of $128 \mathrm{~km} \times 128 \mathrm{~km}$ with a horizontal resolution of $500 \mathrm{~m}$ and periodic lateral boundary conditions. The model domain has 88 vertical levels with spacing between levels of $100 \mathrm{~m}$ in the lower layers and stretching up to $600 \mathrm{~m}$. The domain top lies at $24 \mathrm{~km}$. Initial conditions are based on one representative sounding from the Polarstern (see section 4 for the choice of the sounding). Constant fluxes of heat and moisture of 10 and $150 \mathrm{~W} \mathrm{~m}^{-2}$, respectively, are prescribed at the surface; $150 \mathrm{~W} \mathrm{~m}^{-2}$ represents the high end of observed values over the tropical Atlantic (Yu et al. 2008). Radiation is switched off. To ease the comparison with the satellite observations, the resolution of the output is downgraded to $0.1^{\circ}$. It bears mentioning that, from a resolution point of view, the simulations may be called cloud resolving rather than eddy resolving. However, because no subgrid-scale parameterization is used (except for the Smagorinsky-type diffusion) and for consistency with previous work at similar resolution, we will stick to the term large-eddy simulations.

\section{c. Metrics}

As indicated earlier, both moistening by cumulus congestus and by forced ascent may promote the transition to deep convection. Characteristic time scales associated with these two processes, as well as the actual transition time, will be derived throughout this study. More precisely, we wish to identify and estimate the following time scales:

(i) $\tau_{c}$ : The time needed by clouds to moisten the atmospheric column to a degree that allows the triggering of deep convective cells. The main source of moisture detrained by the clouds comes from surface evaporation.

(ii) $\tau_{w}$ : The time that some form of imposed vertical motion needs to force the formation of deep convective cells. Such ascent may be linked to topographic features, wave activity, convergence due to large-scale flow features, mesoscale circulations (e.g., land-sea breeze, vegetation breeze) or colliding cold pools. The associated moisture convergence enhances the input of moisture into the atmospheric column and forces the transition.

(iii) $\tau_{\%}$ : The time elapsed between the appearance of the first congestus and the first deep clouds.

If $\tau_{*} \ll \tau_{c, w}$, then it suggests that the process associated with the longer time scale is not generally the controlling factor for the development of deep convection.

The above definitions imply that it is the lack of moisture that primarily prevents deep convection initiation (see introduction). Other effects-for example, the need to make clouds unstable relative to their environment (Wu et al. 2009), to reduce entrainment of environmental air into the cloud (e.g., Khairoutdinov and Randall 2006), or to suppress large-scale subsidence (e.g., Takayabu et al. 2010) — have also been mentioned. Some of these effects are hard to disentangle from each other. Whenever possible, only moisture sources will be considered. The possible outcome of both moistening by cumuli congestus and by forced ascent being unable to explain observed transition times would suggest the existence of such alternate mechanisms. In cases where moistening cannot be clearly isolated, it will be assumed that the transition results from moistening of the atmospheric column especially to get lower bounds on $\tau_{c}$ and $\tau_{w}$.

The proposed time-scale analysis depends on an ability to discriminate between congestus and cumulonimbus clouds, both in satellite observations and LES. The classification by Johnson et al. (1999) is followed. Cumuli 

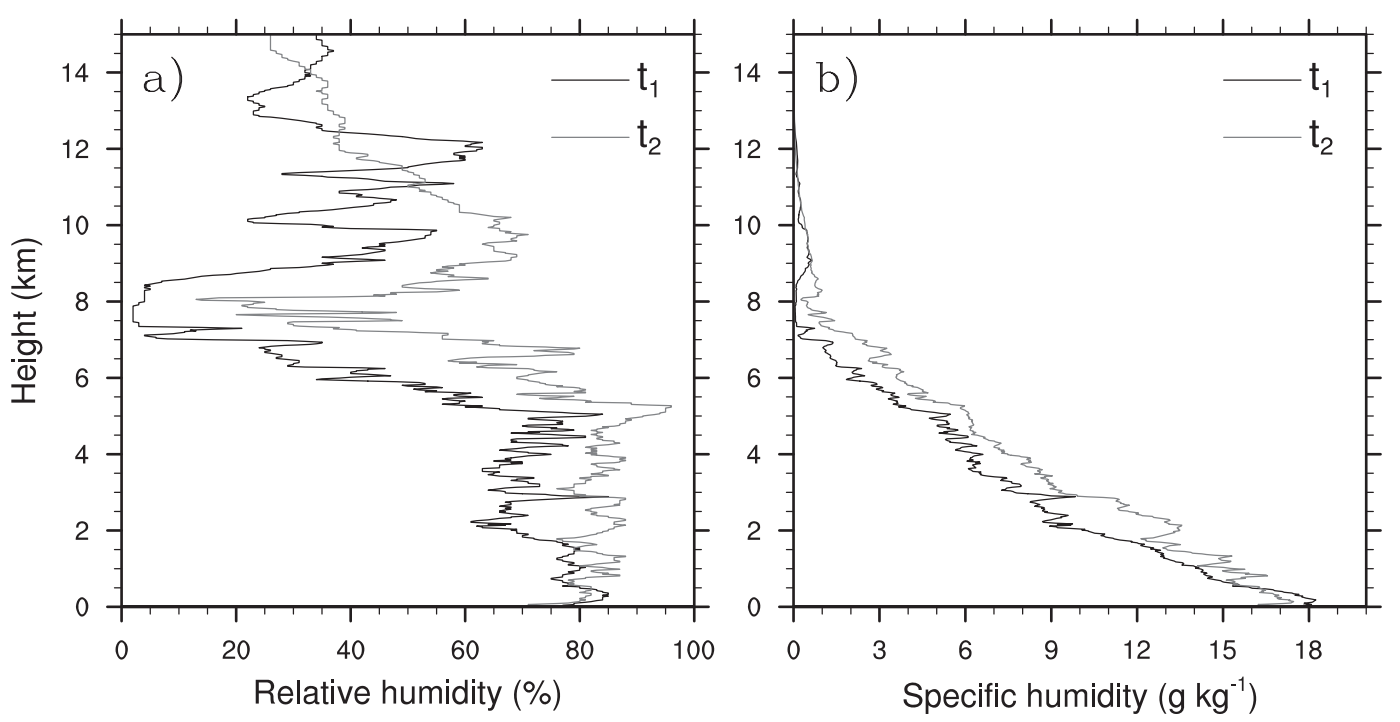

FIG. 2. Profiles of (a) relative humidity (\%) and (b) specific humidity $\left(\mathrm{g} \mathrm{kg}^{-1}\right)$ at times without $\left(t_{1}\right)$ and with $\left(t_{2}\right)$ deep convection.

congestus are defined as clouds with tops between 4 and $9 \mathrm{~km}$. In a tropical atmosphere this approximately corresponds to a cloud-top temperature between 273 and $240 \mathrm{~K}$. The "warm" threshold of $273 \mathrm{~K}$ is chosen specifically to require the formation of supercooled water or ice in congestus clouds. In contrast, shallow cumuli are in essence viewed as warm clouds. Cumulonimbi are identified as clouds with a brightness temperature below $240 \mathrm{~K}$ or a cloud top above $9 \mathrm{~km}$. Masunaga et al. (2005) employed a warmer threshold of $245 \mathrm{~K}$ to distinguish cumulonimbus from congestus, while other studies have employed colder thresholds to isolate deep convective cores.

The time-scale determination further requires keeping track of the cloud field. Here, an Eulerian framework is adopted, which fits well to the picture of an atmosphere in which cumulonimbi develop in regions moistened by cumuli congestus. The analysis is conducted at each grid point (i.e., each $0.1^{\circ}$ ) but is based on the behavior of the measured brightness temperature in a $1^{\circ}$ box centered at that grid point (i.e., a box containing $10 \times 10$ observations). The congestus phase starts when at least two grid points exist in the box with brightness temperature between 273 and $240 \mathrm{~K}$, but no cumulonimbus is present (i.e., no point with brightness temperature below $240 \mathrm{~K}$ ). The deep phase begins when at least four grid points exhibit temperatures below $240 \mathrm{~K}$ for a minimum of $1 \mathrm{~h}$. The congestus phase ends either with the start of the deep phase (this would give $\tau_{*}$ ) or with the dissolution of the congestus clouds. The latter case happens if the box remains void of temperatures between 273 and $240 \mathrm{~K}$ for $1 \mathrm{~h}$. Likewise, if temperatures below $240 \mathrm{~K}$ are absent for at least $1 \mathrm{~h}$, the deep phase is considered finished.

These definitions are necessarily subjective. The criterion for the start of the deep phase is more stringent than the one for the start of the congestus phase. This was chosen in an attempt to favor longer transition phases. The constraints on cloud horizontal extent and lifetime are required because of the pulsing nature of cloud formation. The robustness of the time-scale estimates with respect to the applied thresholding and general approach is examined in the appendix. The performed sensitivity analysis reveals that the conclusions of this study are not affected by such design choices.

\section{Bulk analysis}

In this section, $\tau_{c}$ and $\tau_{w}$ are estimated using bulk formulae, the Polarstern soundings, and the GATE vertical velocities. This provides a first sense on the involved processes and of the possible relevance of congestus moistening.

a. $\tau_{c}$

Figure 2 shows profiles of relative humidity and specific humidity measured at two times. The profiles are seen as representative for different convective phases. The first time $t_{1}$ (1200 UTC 1 May) is characterized by shallow and congestus clouds, while deep clouds populate the sky at time $t_{2}$ (1200 UTC 2 May). Although taken at different locations, both soundings were launched in the equatorial region, at $0^{\circ}, 11.65^{\circ} \mathrm{W}$ and $3.27^{\circ} \mathrm{N}, 14.3^{\circ} \mathrm{W}$ for the first and second soundings, respectively. 
Figure 2 shows that much drier air sits above the planetary boundary layer (i.e., above $\sim 500 \mathrm{~m}$ ) at $t_{1}$ than at $t_{2}$. Relative humidity values are about $20 \%$ smaller at $t_{1}$ and nearly drop to zero around $8 \mathrm{~km}$. These differences explain the presence of shallower clouds at $t_{1}$. As documented in other studies [see especially Derbyshire et al. (2004)], entrainment of dry air effectively limits cloud depth. From a nonentraining parcel point of view, both soundings would actually support deep convection.

Accordingly, the difference in specific humidity apparent in Fig. 2b can be used as proxy for the amount of moistening missing at $t_{1}$ to initiate deep convection. Expressed more formally,

$$
\begin{aligned}
\tau_{c} & =\frac{\Delta q_{v}}{\left(d q_{v} / d t\right)_{c}} \\
\Delta q_{v} & =\frac{1}{z_{2}-z_{1}} \int_{z_{1}}^{z_{2}} q_{v}\left(t_{2}, z\right) d z-\frac{1}{z_{2}-z_{1}} \int_{z_{1}}^{z_{2}} q_{v}\left(t_{1}, z\right) d z
\end{aligned}
$$

and

$$
\left(\frac{d q_{v}}{d t}\right)_{c}=\frac{\overline{w^{\prime} q_{\mathrm{cb}}^{\prime}}}{z_{2}-z_{1}}=\frac{\mathrm{LH}}{L_{v} \rho\left(z_{2}-z_{1}\right)}
$$

with $q_{v}$ specific humidity, $z$ height, $\overline{w^{\prime} q^{\prime}}$ cb moisture flux at cloud base, LH latent heat flux, $L_{v}$ enthalpy of vaporization $\left(2.5 \times 10^{6} \mathrm{~J} \mathrm{~kg}^{-1}\right)$, and $\rho$ air density at cloud base (assumed as $1 \mathrm{~kg} \mathrm{~m}^{-3}$ ).

Equation (1c) approximates the rate at which clouds moisten the atmosphere, which is needed by Eq. (1a). The only source of moisture that can be transported by cloudy updrafts and detrained into the environment stems from evaporation from the sea surface. As such, the moistening rate is limited by the latent heat flux and cumuli congestus primarily act to transport the evaporated water higher up in the troposphere. This is true given that this subsection neglects any input of moisture due to advection (see introduction, section $2 \mathrm{c}$, and section 6). Equation (1c) also assumes that all cloud water detrains into the environment. In reality, some of it falls as precipitation so that $\tau_{c}$ is a lower bound on the congestus-moistening time scale.

Numerically, the following values are inserted into Eqs. (1a)-(1c). The latent heat flux is set to $150 \mathrm{~W} \mathrm{~m}^{-2}$. This represents the high end of observed values over the tropical Atlantic ( $\mathrm{Yu}$ et al. 2008). The layer boundaries $z_{1}$ and $z_{2}$ are set to 500 and $5000 \mathrm{~m}$, respectively, because most congestus clouds may not reach full depth (i.e., $9 \mathrm{~km}$ ). Other choices for $z_{2}$ do not affect our conclusions (see also section 4). This yields $\Delta q_{v}=1.6 \mathrm{~g} \mathrm{~kg}^{-1}$, $\left(d q_{v} / d t\right)_{c}=1.1 \mathrm{~g} \mathrm{~kg}^{-1} \mathrm{day}^{-1}$, and therefore $\tau_{c}=35 \mathrm{~h}$, as listed in Table 1. It thus takes about 1.5 days for cumulus
TABLE 1. Time-scale estimates (h).

\begin{tabular}{ccccccc}
\hline \hline & Polarstern & W0 & W1q & W1 & W5 & MSG \\
\hline$\tau_{c}$ & $35-38$ & & & & & \\
$\tau_{w}$ & $4-18$ & & & & & \\
$\tau_{*}$ & & 10 & 7 & 4 & 1 & $2-4$ \\
\hline
\end{tabular}

congestus to bring the atmosphere into a state supporting deep convection initiation.

Instead of employing the latent heat flux to approximate the moistening rate in Eq. (1c), a bulk mass flux view may be adopted. In this case, Eq. (1c) transforms to

$$
\begin{aligned}
& \left(\frac{d q_{v}}{d t}\right)_{c}=\frac{1}{z_{2}-z_{1}} \int_{z_{1}}^{z_{2}}-\frac{d F_{q_{v}}}{d z} d z=\frac{F_{q_{v}}\left(z_{1}\right)}{z_{2}-z_{1}} \text { and } \\
& F_{q_{v}}\left(z_{1}\right)=\sigma w_{u}\left(z_{1}\right)\left[q_{v_{u}}\left(z_{1}\right)-q_{v_{e}}\left(z_{1}\right)\right]
\end{aligned}
$$

where $F_{q_{v}}$ denotes the cumulus moisture flux, $\sigma$ the cloud cover, and $w$ the vertical velocity. Subscripts $u$ and $e$ stand for updraft and environment, respectively. Equation (2a) again assumes that all cloud water is detrained into the environment and that the cumulus flux is zero at the upper boundary.

Typical values of $\sigma=0.05, w_{u}\left(z_{1}\right)=1 \mathrm{~m} \mathrm{~s}^{-1}$, and $q_{v_{u}}\left(z_{1}\right)-q_{v_{e}}\left(z_{1}\right)=1 \mathrm{~g} \mathrm{~kg}^{-1}$ give $\left(d q_{v} / d_{t}\right)_{c}=$ $1 \mathrm{~g} \mathrm{~kg}^{-1}$ day $^{-1}$ and $\tau_{c}=38 \mathrm{~h}$. This is on the order of magnitude of the previous estimate, which is not surprising given that the cloud base moisture flux in a mass flux scheme will more or less track the surface flux.

b. $\tau_{w}$

The moistening related to forced ascent results from mechanically displacing air from the moister lower atmospheric layers to the drier upper ones, or, equivalently, through moisture convergence. The computation of $\tau_{w}$ thus reads

$$
\begin{aligned}
\tau_{w} & =\frac{\Delta q_{v}}{\left(d q_{v} / d t\right)_{w}}, \\
\Delta q_{v} & =\frac{1}{z_{2}-z_{1}} \int_{z_{1}}^{z_{2}} q_{v}\left(t_{2}, z\right) d z-\frac{1}{z_{2}-z_{1}} \int_{z_{1}}^{z_{2}} q_{v}\left(t_{1}, z\right) d z
\end{aligned}
$$

and

$$
\left(\frac{d q_{v}}{d t}\right)_{w}=\frac{1}{z_{2}-z_{1}} \int_{z_{1}}^{z_{2}}-w \frac{d q_{v}\left(t_{1}, z\right)}{d z} d z,
$$

with $w$ vertical velocity.

Equation (3c) is the analogous to Eq. (1c), whereby the moistening follows from the imposed vertical motion. To evaluate Eqs. (3a)-(3c), $w$ is assumed constant 
in space and time and set to 0.01 and $0.05 \mathrm{~m} \mathrm{~s}^{-1}$, respectively (see section $2 \mathrm{a}$ ). Besides $w$, the specific humidity measured at $t_{1}$ (see Fig. 2b) is used in Eq. (3c) to compute the integral term. As before, $\Delta q_{v}=1.6 \mathrm{~g} \mathrm{~kg}^{-1}$, $z_{1}=500 \mathrm{~m}$, and $z_{2}=5000 \mathrm{~m}$. This leads to $\left(d q_{v} / d t\right)_{w}=$ $2.2 \mathrm{~g} \mathrm{~kg}^{-1}$ day $^{-1}, \tau_{w}=18 \mathrm{~h}$ for $w=0.01 \mathrm{~m} \mathrm{~s}^{-1}$ and $\left(d q_{v} / d t\right)_{w}=11 \mathrm{~g} \mathrm{~kg}^{-1} \mathrm{day}^{-1}, \tau_{w}=4 \mathrm{~h}$ for $w=0.05 \mathrm{~m} \mathrm{~s}^{-1}$.

Comparison of $\tau_{c}$ and $\tau_{w}$ readily shows that $\tau_{w}$ is much shorter than $\tau_{c}$. Already a very weak imposed ascent is by a factor of 2 more efficient at triggering deep convection than pure congestus moistening. Although the time scales depend upon the prevailing moisture deficit $\Delta q_{v}$, their ratio does not for given surface moisture fluxes and initial profiles of specific humidity. It follows that, for congestus moistening to become important, observed transitions should be slow and the atmosphere relatively quiescent over a day at least. A vertical velocity of $0.005 \mathrm{~m} \mathrm{~s}^{-1}$ gives for instance a $\tau_{w}$ equal to $\tau_{c}$. The quiescence of the atmosphere is investigated in section 6 .

Equations (3a)-(3c) assume that only moisture is advected into the region-that is, only $q_{v}$ feels $w$. This is not true in reality, especially under large-scale convergence. If the full atmosphere is forced to rise, the atmosphere cools, which destabilizes the column. This destabilization may be more efficient than pure moistening to trigger deeper clouds, or at least help to sustain a faster transition. Based on the previous computation for $w=0.01 \mathrm{~m} \mathrm{~s}^{-1}$, the troposphere ascends by $650 \mathrm{~m}$ in $18 \mathrm{~h}\left(=\tau_{w}\right)$. The induced cooling amounts to $2.6 \mathrm{~K}$ given a lapse rate of $4 \mathrm{~K} \mathrm{~km}^{-1}$. The convective dynamics will not allow such a large cooling, implying that the atmosphere will break into the deep regime before $18 \mathrm{~h}$.

\section{Large-eddy simulations}

The previous section employed bulk formulas to constrain $\tau_{c}$ and $\tau_{w}$. One issue is that this approach does not allow an exact determination of the appearance time of congestus and cumulonimbus clouds, respectively. Another issue relates to the unknown vertical extent of the layer to be moistened or to the unknown effect of precipitation on the estimated time scales. Here, we make use of the ability of the UCLA-LES (see section $2 b$ ) to explicitly resolve convection to derive a second set of time scales. The latter can also more easily be compared to observed transition times (see section 5).

The time scales are estimated from an analysis of four experiments whose designs are inspired by the results of section 3. The simulations are denoted W0, W1, W1q, and W5. They all start from the Polarstern sounding $t_{1}$ (see Fig. 2) with sensible and latent heat fluxes set to 10 and $150 \mathrm{~W} \mathrm{~m}^{-2}$, respectively. In the $\mathrm{W} 0$ experiment no large-scale vertical velocity is imposed on the flow. This is akin to the simulations presented in Waite and Khouider (2010), albeit starting from a different initial sounding, using fixed surface fluxes instead of fixed sea surface temperature, and no radiation. The deepening of the convective layer in this case results in theory from moistening by clouds, as discussed in section 3a. In practice, formation of cold pools and possible destabilization of the atmosphere may further foster deep convection. The derived transition time thus underestimates a pure moistening time scale, although Waite and Khouider (2010) found a dominant effect of the moistening process. In the remaining three experiments, a constant large-scale $w$ of $0.01 \mathrm{~m} \mathrm{~s}^{-1}$ in $\mathrm{W} 1$ and $\mathrm{W} 1 \mathrm{q}$ as well as of $0.05 \mathrm{~m} \mathrm{~s}^{-1}$ in W5 is imposed. The vertical velocity acts below $10 \mathrm{~km}$ in the vertical and serves to mimic forced ascent (see section 3b). It is imposed on temperature and humidity in W1 and W5 but only on humidity in W1q. Comparison of W1 and W1q serves to better isolate the effect of cooling, which generally accompanies forced ascent, as discussed in the previous section. Like in W0, cold pools form in W1, W1q, and W5 and may help the transition.

Figures $3 \mathrm{a}, \mathrm{b}$ show profiles of potential temperature and specific humidity obtained in W0, W1, W1q, and W5 at the time of deep convection initiation as well as the Polarstern soundings at $t_{1}$ and $t_{2}$. The time of deep convection initiation is diagnosed, as alluded to in section 2c, by downgrading the resolution of the LES output to the MSG resolution and requiring the presence of at least four points in the domain with brightness temperature below $240 \mathrm{~K}$ for $1 \mathrm{~h}$. Except for the lowest $1 \mathrm{~km}$ of the atmosphere, the simulated values remain close to the sounding curves. This good agreement is notable because the LES simulations were not specifically designed to reproduce the observations.

Not surprisingly, W0 and W1q are equally warm and, except for the lowest $1.5 \mathrm{~km}$, still close to the initial sounding. W1, W5, and the Polarstern sounding at $t_{2}$, in opposition, exhibit colder temperatures. The differences amount to about $0.5 \mathrm{~K}$ for the Polarstern sounding at $t_{2}$ and $1 \mathrm{~K}$ for W1 and W5 compared to the Polarstern sounding at $t_{1}$. With deep convection further developing, all the simulated profiles begin to warm. The W1 and W5 curves shift toward the Polarstern curve at $t_{2}$, whereas W0 and W1q remain continuously too warm. This suggests that the Polarstern sounding at $t_{2}$ may be actually more representative of an atmosphere into the deep phase than at its initiation.

In terms of specific humidity W0, W1, and W5 attain similar values. The specific humidity averaged over the lower troposphere (between 0.5 and $5 \mathrm{~km}$ ) amounts to $10.3,10.4$, and $10.6 \mathrm{~g} \mathrm{~kg}^{-1}$, respectively, and the amount 

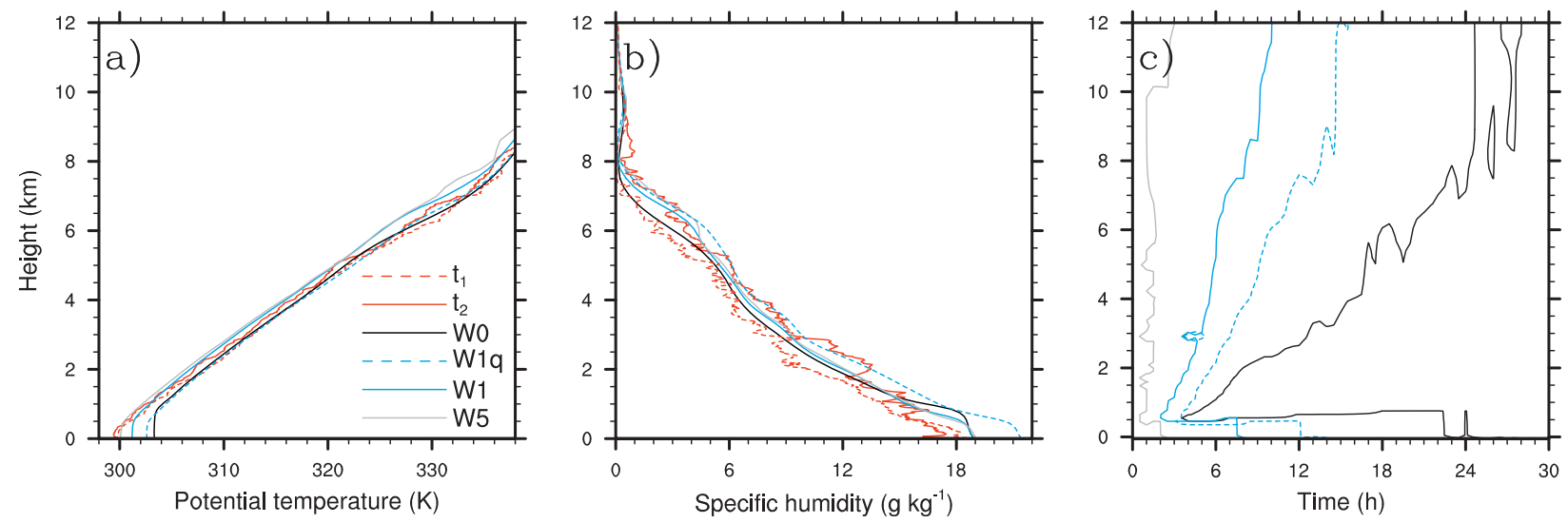

FIG. 3. Profiles of (a) potential temperature (K) and (b) specific humidity $\left(\mathrm{g} \mathrm{kg}^{-1}\right)$ at time of deep convection initiation as well as (c) condensate (precipitating and nonprecipitating) evolution in simulations W0 (solid black), W1 (solid blue), W1q (dashed blue), and W5 (gray). The dashed red and solid red lines in (a),(b) represent the Polarstern soundings at $t_{1}$ and $t_{2}$, respectively. The contour lines in (c) visualize the deepening of the cloud layer and are drawn at $10^{-4} \mathrm{~g} \mathrm{~kg}^{-1}$. The simulation results are averaged horizontally and over 30-min intervals.

of moistening occurring during each congestus phase to $1,1.2$, and $1.4 \mathrm{~g} \mathrm{~kg}^{-1}$, respectively. On the other hand, the specific humidity values in W1q appear much larger. The lower troposphere moistens by $2.3 \mathrm{~g} \mathrm{~kg}^{-1}$ in this case. The larger value follows from similar relative humidities but warmer temperatures as compared to W1. It becomes evident that a pure moistening argument, as articulated in the introduction, is not sufficient to explain deep convection initiation in all the simulations. Interestingly, the required moistening is smallest in W0.

Figure $3 \mathrm{c}$ displays the corresponding cloud evolution and transition to deep convection. Cloud tops reach $9 \mathrm{~km}$ almost instantaneously in W5, followed by W1, W1q, and W0. Figure 3c clearly demonstrates that the transition from congestus to cumulonimbus is slowest in W0, even when the large-scale forcing is weak and only allowed to act on $q_{v}$ (see W1q). Comparison of W1q and W1 indicates that the adiabatic cooling associated with the forced ascent accelerates the transition by $40 \%$. Cumuli congestus obviously cannot destabilize the atmosphere as effectively, which makes it even more difficult for them to compete with forced ascent. As a further possible advantage, W1q, W1, and W5 rain more heavily. This yields stronger cold pools, larger clouds, smaller entrainment rates, and possibly deeper clouds (Khairoutdinov and Randall 2006).

Whereas the methodology adopted in section 3 did not allow for a specific distinction between the onset of shallow, congestus, and cumulonimbus clouds, such distinctions are possible in W0, W1, W1q, and W5. This allows computation of an LES-based $\tau_{*}$ using the evolution of brightness (cloud-top) temperatures in a $1^{\circ} \times 1^{\circ}$ box as discussed in section $2 \mathrm{c}$. In so doing it follows the same procedure as will be done in the analysis of the satellite data in the next section. The results of the computation are listed in Table 1 . Simulated $\tau_{*}$ amounts to $10 \mathrm{~h}$ in W0, $7 \mathrm{~h}$ in W1q, $4 \mathrm{~h}$ in W1, and $1 \mathrm{~h}$ in W5.

Table 1 confirms the relative ease to accelerate the development of convection by controlling the magnitude of $w$. The other possibility to control and especially to reduce $\tau_{*}$, which is the only possible way in W0, requires reducing the prevailing moisture deficit-that is, starting from moister conditions. The question of the representativeness of the profiles driving the LES simulations and the convective development thus arises.

In terms of relative humidity, both the soundings at $t_{1}$ and $t_{2}$, and at the time of convection initiation in the LES simulations are not atypical for Atlantic conditions. Casey et al. (2009) studied the climatology of dry-air layers from Atmospheric Infrared Sounder (AIRS) observations and found a $5 \%-10 \%$ frequency of dry-air layers during spring over the tropical Atlantic. A dry-air layer was defined as relative humidity values below $20 \%$ between 600 and $400 \mathrm{hPa}$. In this respect, the chosen initial Polarstern profile, with its relative humidity values above $60 \%$ up to $450 \mathrm{hPa}$ (see Fig. 2 at $t_{1}$ ), appears fairly moist. The latter relative humidity values fall well in the range of frequently observed relative humidities as plotted in Casey et al. (2009, their Fig. 1). The same is true concerning the profiles at later times.

Several studies have also tried to relate relative humidity and precipitation strength (e.g., Bretherton et al. 2004; Holloway and Neelin 2009). The results of such studies may be used to infer two representative relative humidity values: one characterizing the onset of congestus clouds and one for the onset of cumulonimbus. The comparison to such studies can nevertheless only be suggestive because it is not clear where the congestus 
phase fits in. Bretherton et al. (2004) found an exponential relationship between monthly-mean precipitation $P_{m}$ and column-mean relative humidity $r$ of the form [see their Eq. (2)] $P_{m}=\exp [11.4(r-0.522)]$. Masunaga (2012) employed Tropical Rainfall Measuring Mission (TRMM) observations over the tropics and assigned precipitation rates of 4 and $14 \mathrm{~mm}$ day $^{-1}$ to the cumuli congestus and to the cumulonimbi, respectively. Inserting these two values in Eq. (2) of Bretherton et al. (2004) gives $r=65 \%$ for the congestus phase and $r=75 \%$ for the deep phase. The corresponding values for the Polarstern soundings are $68 \%$ and $78 \%$, respectively, and for the W0 simulation $72 \%$ and $73 \%$. The column water vapor peaks at $52 \mathrm{~mm}$ at time of congestus clouds and at $54.5 \mathrm{~mm}$ at time of cumulonimbi in Masunaga (2012). The values are 52.9 and $58.9 \mathrm{~mm}$ for the two Polarstern soundings and 59.4 and $61.4 \mathrm{~mm}$ in W0. Whereas Masunaga (2012) considered the whole tropics, Holloway and Neelin (2009) focused on Naru. In that case, the column water vapor reaches $60 \mathrm{~mm}$ at time of cumulus congestus and $66 \mathrm{~mm}$ by deep convection. Hence, depending on the chosen reference, the difference in humidity between the two Polarstern soundings may be seen as plausible or too large for a typical humidity difference between the onset of congestus and the onset of deep clouds. In opposition, the corresponding humidity difference in $\mathrm{W} 0$ appears not unrealistic and rather on the lower side.

Finally, the LES estimates listed in Table 1 may be contrasted to results from other LES studies. Waite and Khouider (2010) indicated a congestus phase starting after $20 \mathrm{~h}$ of simulation and lasting up to $32 \mathrm{~h}$, yielding an approximate transition time of $12 \mathrm{~h}$. The resulting longer time scale is not surprising given the use of a very dry atmospheric profile with relative humidity dropping below $20 \%$ above $2 \mathrm{~km}$ (see their Fig. 1c). They also performed experiments initialized from a very moist atmospheric profile. Even in that case, the transition time does not drop below $6 \mathrm{~h}$. In the simulation of Kuang and Bretherton (2006) congestus clouds need 3 days to sufficiently moisten the atmosphere. In contrast to Waite and Khouider (2010), a subsidence velocity is imposed below $1.5 \mathrm{~km}$ in Kuang and Bretherton (2006), making it more difficult for clouds to deepen. Khairoutdinov et al. (2009) simulated one episode from the GATE period, which includes prescribed large-scale forcing. Cumuli congestus transition almost instantaneously to cumulonimbi (see their Fig. 1). Finally, Khairoutdinov and Randall (2006) simulated an idealized version of the Large-Scale Biosphere-Atmosphere Experiment (LBA) case, aimed at representing the development of convection over tropical land area. Although not forced, the congestus phase lasts less than $1 \mathrm{~h}$ (see their Fig. 1). Khairoutdinov and
Randall (2006) nevertheless argued that the transition is dynamically (through cold pools) and not thermodynamically (through moistening and preconditioning) controlled.

It bears mentioning that several studies have documented the sensitivity of simulated deep convection to aspects of the experimental setup (e.g., Bryan et al. 2003; Waite and Khouider 2010). Coarse grid resolution especially tends to speed up the transition. This has an impact on the calculated $\tau_{*}$ but not on the underlying conclusion that even weak ascent more efficiently initiates deep convection than congestus clouds. Moreover, this sensitivity to resolution suggests that, if anything, the UCLA-LES underestimates $\tau_{*}$. Likewise, use of other definitions for $\tau_{*}$ does not change the essence of the difference between the three simulations-a point that is further discussed in the appendix.

\section{Observed transition}

Even if congestus moistening proceeds at a slow pace, it is known that long-lived widespread congestus clouds exist in the tropics. Geostationary satellite data, whose resolution is fine enough to explore real transitions from congestus to cumulonimbus clouds, are explored in this section. The results are unaffected by the methodology employed to compute $\tau_{*}$, as discussed in detail in the appendix.

\section{a. Global view: $\tau_{*}$}

Figure 4 displays the number of total (deep plus congestus) events as well as pure deep events detected during May 2010 (see section 2c for a definition of congestus and deep phases and for a description of the detection algorithm). Not surprisingly, Fig. 4a reveals a frequent occurrence of mid- to deep events over the tropics. Most regions experience new developing cloud systems on a 1-2-day basis. Peak occurrence rates are twice per day. Only the cold waters of the Eastern boundary current regions, or the dry areas of the Sahara, remain void of cumulus congestus and cumulonimbus.

Figure $4 \mathrm{~b}$ shows that deep convection is concentrated in a narrow band over the Atlantic Ocean, between $2^{\circ}$ and $10^{\circ} \mathrm{N}$, as expected. This marks the position of the ITCZ during this time of the year. Over the landmasses, deep clouds are prominent between $10^{\circ} \mathrm{S}$ and $10^{\circ} \mathrm{N}$. Extensive regions show evidence of daily initiation of deep convection in Fig. 4b.

Figure 5 displays $\tau_{*}$ as estimated based on the evolution of observed brightness temperatures and averaged over May 2010. Figure 5 highlights very short transition times on the order of a few hours. Longer transition times, with values up to $10 \mathrm{~h}$, can only be found outside 


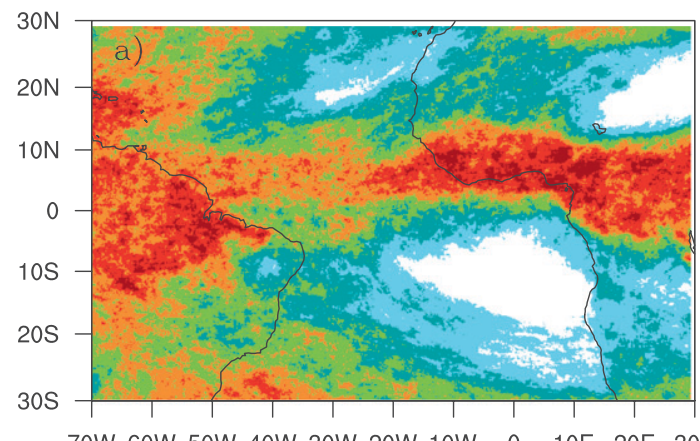

70W 60W 50W 40W 30W 20W 10W 0 10E 20E 30E

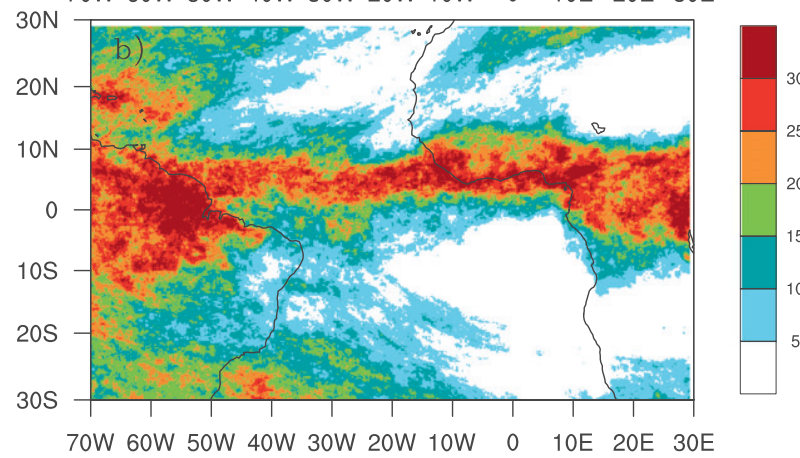

FIG. 4. Number of (a) congestus and deep events as well as (b) pure deep convective events derived from 1 month of MSG data.

the $10^{\circ} \mathrm{S}-10^{\circ} \mathrm{N}$ belt, where the occurrence of deep events is rare (see Fig. 4b). A more detailed inspection of Fig. 5 further reveals that typical regional differences exist in $\tau_{*}$. The values scatter around $2 \mathrm{~h}$ over northern South America and central Africa versus 4 h over the Atlantic Ocean. This implies a faster transition over land than over ocean. There is also a hint toward shorter $\tau_{*}$ over the Atlantic ITCZ (see the region enclosed in white in Fig. 5).

These findings do not support the idea that preconditioning by congestus clouds is important for the onset of deep convection. In a regime controlled by congestus moistening, the transition should be faster over ocean than over land. This follows from the larger surface moisture fluxes over the ocean and from the generally moister atmospheric column. Most importantly, a comparison of the values obtained in Fig. 5 with the previous time-scale estimates (see Table 1) stresses the difference in magnitude that exists between the time needed by cumulus congestus to sufficiently moisten the atmosphere $(10 \mathrm{~h})$ and the actual time needed by cumulus congestus to develop into cumulonimbus $(2-4 \mathrm{~h})$. This comparison suggests that deep convection primarily responds to dynamical forcing over the tropics.

Figure 5 gives a slightly skewed view on typical $\tau_{*}$ values because rare and long events project heavily on the mean. Figure 6 shows the histogram resulting from sampling $\tau_{*}$ over May 2010 and over the full domain

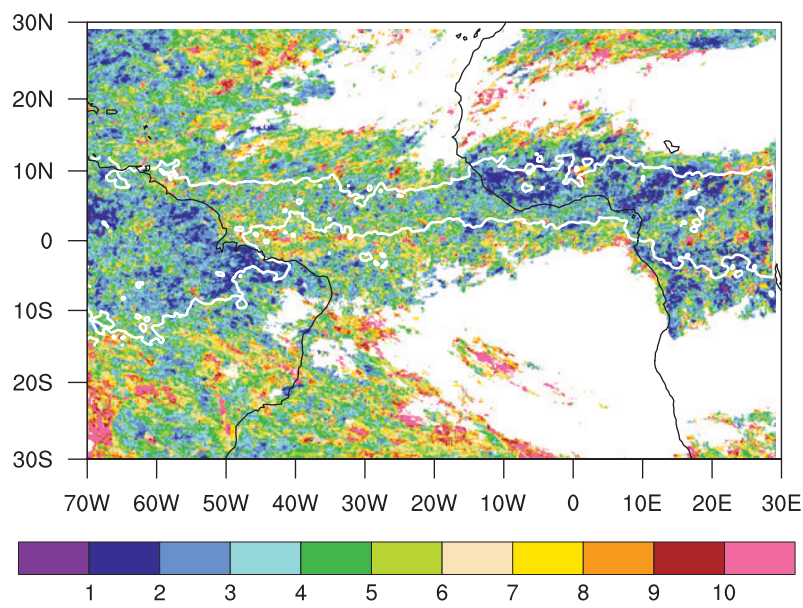

FIG. 5. Map of $\tau_{*}(\mathrm{~h})$ derived from MSG data and averaged over May 2010. Points with less than five transitions over the full month are masked. The white line encloses the main region of deep convective activity.

(Fig. 6a) as well as over zonal subregions (Fig. 6b). The data have also been stratified between land and ocean.

Figure 6a reinforces Fig. 5: 45\% of the observed $\tau_{*}$ values lie below $2 \mathrm{~h}$ over land, and $54 \%$ are below $4 \mathrm{~h}$ over ocean. The percentage climbs up to $90 \%$ by $9 \mathrm{~h}$ both over land and ocean. The situation is even more dramatic over the main region of deep convective activity, as visible in Fig. 6b: 53\% (62\%) of all transitions occur in less than $2 \mathrm{~h}(4 \mathrm{~h})$ over land (ocean). In a mere $7 \%$ of all cases, the transition approaches time scales favorable for moistening (i.e., $10 \mathrm{~h}$ and longer).

Figure 6 only includes congestus clouds that develop into deep convection. In fact, congestus clouds are often in a terminal state: $60 \%$ of the recorded congestus events never transition. The portion drops to about $35 \%$ for the zonal subregions of Fig. 6b. Analyzing $1 \mathrm{yr}$ of CloudSat and Moderate Resolution Imaging Spectroradiometer (MODIS) data, Luo et al. (2009) also found that about $60 \%-70 \%$ of the tropical cumuli congestus stand in a terminal state.

It can thus be stated that the probability of rapid transition is high, as is the probability of no transition. In between, the probability decays exponentially with cumuli congestus rarely developing into cumulonimbi after $20 \mathrm{~h}$. Yet, more than $10 \%$ of all terminal cumuli congestus have a lifetime of more than $20 \mathrm{~h}$ (not shown). The observation that cumuli congestus either rapidly or never grow into cumulonimbus does not support the congestus moistening hypothesis.

Further evidence can be collected from a more detailed consideration of Fig. 6. Figure 6 seems to suggest that long-lived congestus clouds are less probable to transition to deep convection than short-lived ones. This might be an artifact simply resulting from the diminishing 

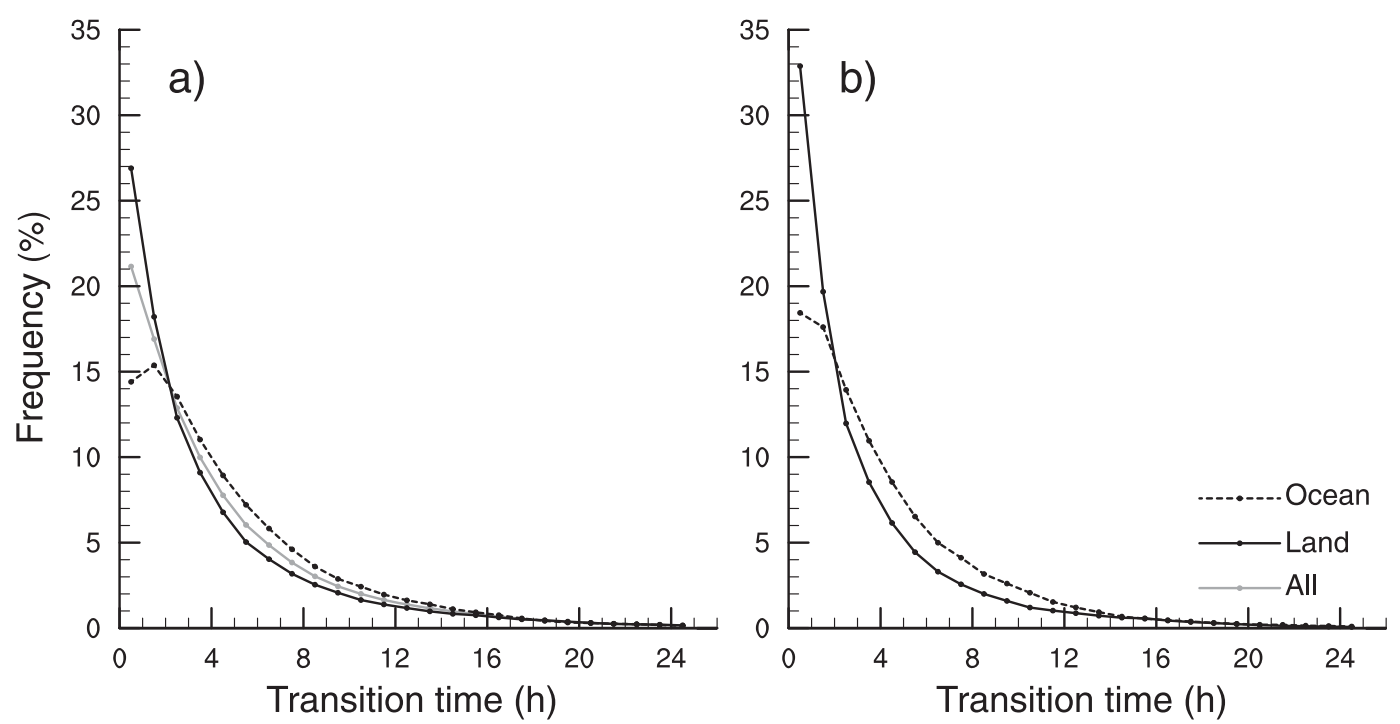

FIG. 6. Frequency distribution (\%) of $\tau_{*}$ (h) for (a) the full domain and (b) zonal subregions. Gray stands for all points, dashed black for oceanic points, and black for land points. The zonal bands in (b) are between $2.5^{\circ}$ and $10^{\circ} \mathrm{N}$ for the oceanic curve and between $10^{\circ} \mathrm{S}$ and $15^{\circ} \mathrm{N}$ for the land curve. Only congestus clouds that transition to deep convection are considered. This represents about $40 \%$ of all events in (a) and $65 \%$ in (b).

number of transient congestus events with increasing lifetimes. To investigate this, ratios of conditionally sampled transient congestus to conditionally sampled terminal congestus are computed. If cumuli congestus are present for 4 h over a region, they have a $29 \%$ chance to transition to deep convection in the next $2 \mathrm{~h}$ and a $71 \%$ chance to disappear. The likelihood of deepening slightly decreases to $26 \%$ for congestus clouds present for $8 \mathrm{~h}$. Hence, the longer-lived congestus clouds are not more prone to deepen. Expressed in slightly different words, more potential moistening does not enhance the probability of deep convection initiation.

Along similar lines, Fig. 6 allows computation of the conditional probability of encountering cumulus congestus $n$ hours in advance of deep convection over a certain region. The probability is denoted $P(n)$. The expectation is that, if cumuli congestus locally precondition deep convection, they should more frequently precede deep clouds than clear sky. Given cumulonimbi triggered at a certain time $t$ over a certain region, the chance that congestus clouds were already present, for example, $4 \mathrm{~h}$ before $t$ simply corresponds to the ratio between events having transition times longer than $4 \mathrm{~h}$ and events with transition times shorter than $4 \mathrm{~h}$. Thus, $P(n)$ can be computed as follows (in its discretized form):

$$
P(n)=\frac{\sum_{\tau_{*}=n}^{\tau_{*}=24} P\left(\tau_{*}\right)}{\sum_{\tau_{*}=n-1}^{\tau_{*}=n-1} P\left(\tau_{*}\right)},
$$

where $P\left(\tau_{*}\right)$ stands for the probability (or frequency of occurrence) of a certain transition time $\tau_{*}$ and can be read directly from Fig. 6a or Fig. 6b. A value of 1 means equal chance to find congestus or clear sky in advance of deep convection. Numerical examples yield $P(4)=0.64$, $P(5)=0.46$, and $P(6)=0.34$ with the values for the full domain (gray curve in Fig. 6a). Very low probabilities, with $P(4)=0.36$, are obtained for the land region in Fig. $6 \mathrm{~b}$ (see black curve). The probability that a region without any cumulus congestus develops cumulonimbi $4 \mathrm{~h}$ later is also computed and compared to the probability that a region with cumuli congestus develops cumulonimbi $4 \mathrm{~h}$ later. Both probabilities do not differ significantly, meaning that cumulus congestus does not increase the likelihood for deep convection development.

Figures 5 and 6 consider neither the horizontal scale of the convective systems nor the possible relationship between transition time and horizontal extent. This aspect is investigated with Fig. 7. Figure 7a shows $\tau_{*}$ binned and averaged as a function of the duration of the deep phase. The latter is defined as indicated in section $2 \mathrm{c}$ and serves as a surrogate for the horizontal scale of the convective disturbances. Bigger systems are typically longer lived. Figure 7 a clearly reveals that $\tau_{*}$ increases with increasing horizontal scale. Note that the number of recorded events also strongly decreases with increasing horizontal scale.

Figure $7 \mathrm{~b}$ complements this view by showing the mean $\tau_{*}$ computed for boxes of increasing size, from $1^{\circ} \times 1^{\circ}$ to $10^{\circ} \times 10^{\circ}$. The number of counts used to define congestus and deep phases is adapted to keep the ratio between 

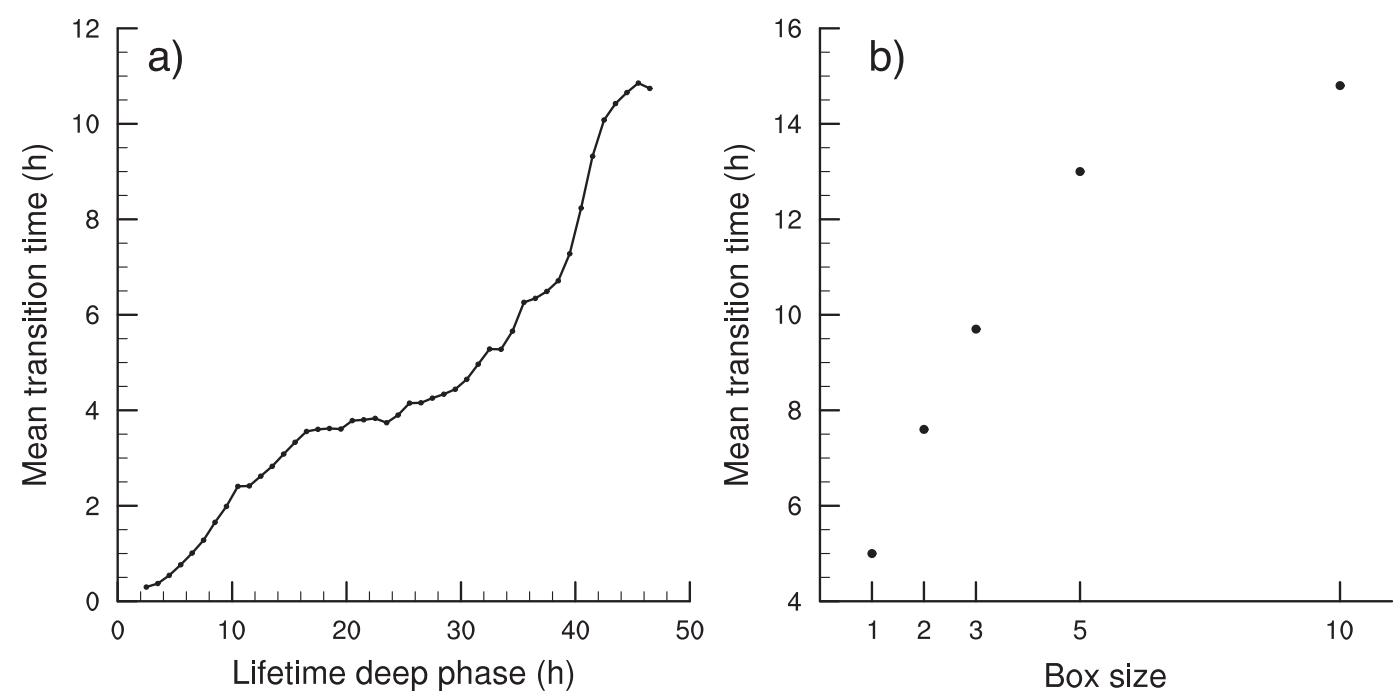

FIG. 7. Plots of (a) $\tau_{*}(\mathrm{~h})$ averaged as function of the length of the deep phase (h) and (b) mean $\tau_{*}(\mathrm{~h})$ for different box sizes $\left(1^{\circ} \times 1^{\circ}, 2^{\circ} \times 2^{\circ}, 3^{\circ} \times 3^{\circ}, 5^{\circ} \times 5^{\circ}\right.$, and $\left.10^{\circ} \times 10^{\circ}\right)$.

congestus (or cumulonimbus) cloud coverage and area of the box constant. The larger the box, the larger the minimum scale of the captured system and the fewer events recorded. The mean is computed over all $\tau_{*}$ independently of their frequency of occurrence and thus is skewed toward longer and infrequent events. This explains, for instance, the value of $5 \mathrm{~h}$ found for the $1^{\circ} \times 1^{\circ}$ box in Fig. 7b.

Figure $7 \mathrm{~b}$ corroborates Fig. 7a. Larger deep convective disturbances are preceded by a longer congestus phase. Given that the ratio between congestus and deep clouds remains constant in Fig. $7 \mathrm{~b}$ across scales, $\tau_{*}$ should be scale invariant if congestus moistening were the main driver of the transition. This is not true for a dynamically forced transition. First, spinning up largerscale circulation takes more time. Second, some dynamical forcings (e.g., gravity waves) can generate much more intense vertical motions on smaller scales. Figure $7 \mathrm{~b}$ thus indicates that convective disturbances of scale smaller than about $200 \mathrm{~km}$ are unlikely to be triggered by congestus moistening. As bigger systems approach longer $\tau_{*}$, a significant contribution of congestus moistening cannot be excluded, although the fact that $\tau_{*}$ keeps on increasing in Fig. 7 might suggest otherwise.

\section{b. Case study}

Besides looking at the transition statistics in terms of $\tau_{*}$, it is instructive to examine one particular transition over land and over ocean. Figure 8 displays the evolution of clouds, captured in a 1-h time interval, for a $10^{\circ} \times$ $10^{\circ}$ region located in Africa (Figs. 8a-g) and in the Atlantic (Figs. 8h-n). The clouds are classified as cumulus congestus (purple shading) and cumulonimbus (orange shading) based on their brightness temperature (see section 2c).

Figures $8 \mathrm{a}-\mathrm{g}$ emphasize the poor spatial correlation that exists between areas of cumulus congestus and of cumulonimbus. Congestus clouds mainly populate the southwestern quadrant of the domain, as marked by the purple ellipse. In opposition, deep convection primarily develops over the remaining three quadrants during the course of the day.

Figures $8 \mathrm{a}-\mathrm{g}$ also confirm the rapid nature of the convective development over land. Contrasting Figs. 8a and $8 \mathrm{c}$, it is evident that, $2 \mathrm{~h}$ before deep convection, no congestus cloud exists in a radius of about $250 \mathrm{~km}$ around the future cumulonimbus location (see orange ellipse). The clouds deepen and expand very rapidly. They also seem to remain stationary, at least during their early development stage. This gives some support to the chosen Eulerian approach (see appendix for further discussion).

Similar conclusions can be deduced for the Atlantic region; see Figs. 8h-n. Assuming a dominant effect of congestus moistening and given, for instance, Fig. 8i, the purple ellipse would represent the most likely location for a subsequent triggering of deep convection. Also, no advection of either cumulonimbus or congestus clouds in the orange ellipse can be recognized. As compared with the situation over land, isolated congestus clouds already populate the region of future deep convection $4 \mathrm{~h}$ before triggering (see the region enclosed by the orange ellipse in Figs. $8 \mathrm{~h}-\mathrm{n}$ ). This further confirms Fig. 5 and the time-scale analysis. 


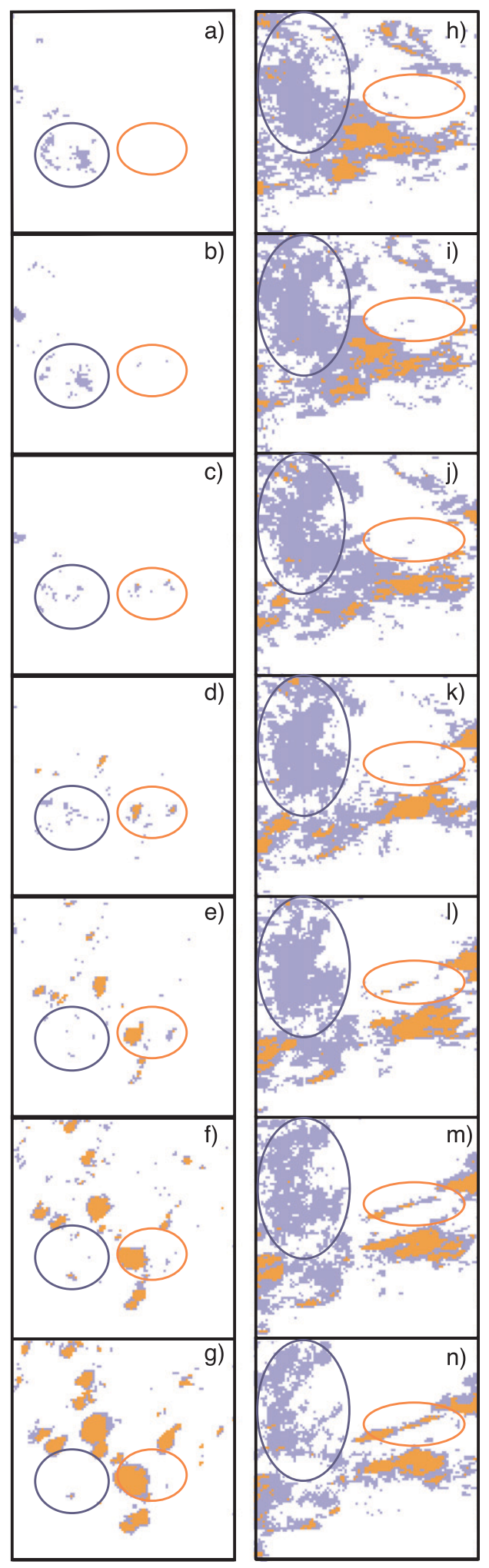

FIG. 8. Time evolution (1-h interval) of the cloud field over a $10^{\circ} \times$ $10^{\circ}$ region located in (a)-(g) Africa and (h)-(n) the midtropical Atlantic. Cumuli congestus are in purple and cumulonimbi in orange. Deep convection develops in the region delimited by the orange ellipse, while the purple ellipse highlights the main location of the congestus population. Wind is blowing from east to west (i.e., right to left).

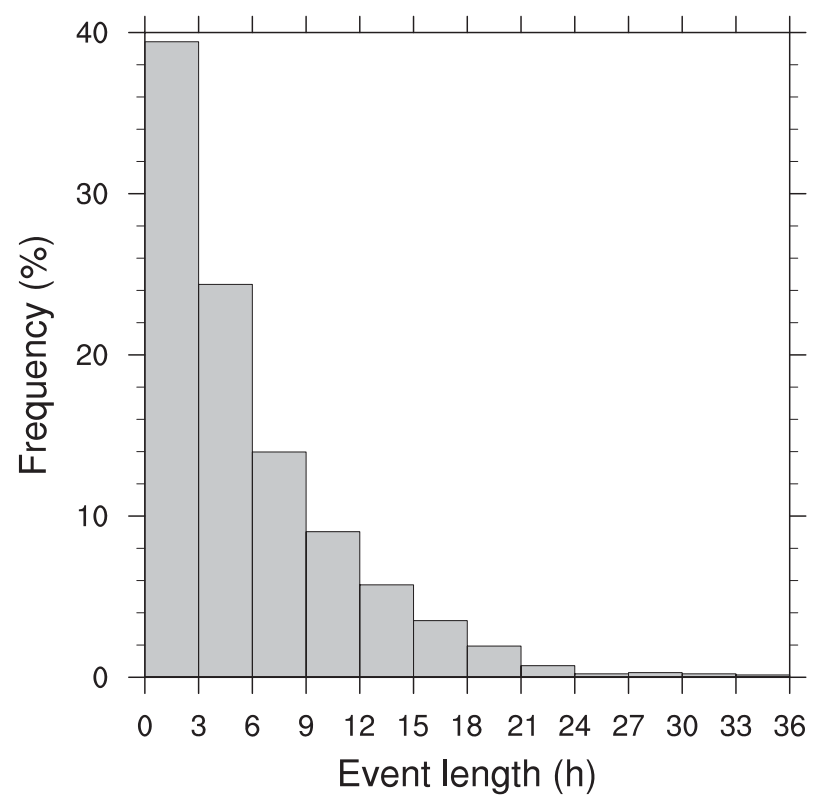

FIG. 9. Frequency distribution (\%) of the duration (h) of events with weak large-scale forcing derived from GATE data. Weak large-scale forcing is defined as $-0.005<w<0.005 \mathrm{~m} \mathrm{~s}^{-1}$, with $w$ averaged in the vertical below $10 \mathrm{~km}$. Note that $w$ is only available on a 3-hourly basis.

\section{Discussion}

The above analysis suggests that a local preconditioning of the atmosphere, through the action of cumulus congestus, is likely not a dominant factor in the transition between cumulus congestus and cumulonimbus. Of course, the exclusive moistening by congestus clouds can trigger deep convection, as was evident in the W0 simulation. However, the relative inefficiency of this process requires a quiet atmosphere to be effectivethat is, an atmosphere devoid of strong vertical motion for time scales on the order of $10 \mathrm{~h}$ at least (see Table 1).

Figure 9 assesses the quiescence of the atmosphere from a GATE perspective. Figure 9 shows a histogram of the duration of events with weak large-scale forcing. The latter events are defined as $-0.005<w<$ $0.005 \mathrm{~m} \mathrm{~s}^{-1}$. A vertical velocity of $0.005 \mathrm{~m} \mathrm{~s}^{-1}$ implies that $\tau_{w}=35 \mathrm{~h}$. This is in the range of $\tau_{c}$. Note that $w$ is only available on a 3 -hourly basis.

Figure 1 already indicates that the tropical Atlantic is generally not very quiescent: only $25 \%$ of the time, the large-scale vertical velocity lies in the range $-0.005<$ $w<0.005 \mathrm{~m} \mathrm{~s}^{-1}$. Figure 9 complements this view. Forty percent of the latter events die within $3 \mathrm{~h}$, as probably associated with the transition from a subsidence-dominated to a convergence-dominated regime (or vice versa). Only $20 \%$ of the quiescent events, or four times for each of the GATE grid boxes over a time period of 20 days, last 
longer than $9 \mathrm{~h}$. Hence, assuming that disturbances only develop through congestus preconditioning and given the observed distribution of large-scale vertical motion over the tropical Atlantic, the genesis of four disturbances can be assigned to congestus preconditioning. This is much less than the number of observed events (see Fig. 4b).

Corresponding measurements over the tropical landmasses are not available. However, convection over land undergoes an intense diurnal cycle, which is an indirect result of the diurnal cycle in solar insolation. The daily rhythm imposes strong constraints on the timing of convection with a short window for deep convection initiation. This, in turn, does not favor processes acting on long time scales.

Although the present analysis does not support a local preconditioning of deep convection by congestus clouds, it is useful to note that areas under cumulus congestus will tend to moisten with time. Even if the congestus clouds may have disappeared many hours before the start of a new deep convection cycle, the deposed moisture anomalies can survive them for many hours. Some of this moisture may also be advected by the flow into regions of deep convection. In this sense, congestus clouds may avoid a too-fast drying of the tropical atmosphere and indirectly allow a faster transition to deep convection through imposed vertical motion. But they do not enhance the probability for transition, because the transition is more efficient under dynamical forcing.

The analysis also focused on the vertical transport of moisture by cumulus congestus, which is in line with the common view of congestus clouds slowly moistening the atmosphere (see introduction). Congestus clouds additionally induce low-level convergence and midlevel divergence through their convective heating. Strictly speaking, this represents a dynamical effect and thus belongs to the forced ascent category (i.e., to our second hypothesis). Schumacher et al. (2008) estimated the divergence associated with cumulus congestus from TRMM observations for the Kwajalein Experiment (KWAJEX). Convergence decreases from $3 \times 10^{-6}$ to $0.5 \times 10^{-6} \mathrm{~s}^{-1}$ from the surface to $900 \mathrm{hPa}$ and stays around $0.5 \times$ $10^{-6} \mathrm{~s}^{-1}$ up to $800 \mathrm{hPa}$ (see their Fig. 8). Employing the conservation of mass and averaging the obtained vertical velocity below $800 \mathrm{hPa}$ for comparison with the LES simulations of section 4 yield a vertical velocity of about $0.002 \mathrm{~m} \mathrm{~s}^{-1}$. This implies a transition time that is slower than with $w=0.01 \mathrm{~m} \mathrm{~s}^{-1}$. Haertel et al. (2008) performed a vertical-mode decomposition of the convective heating. The divergence profile associated with the sum of shallow and congestus modes and derived from a composite of the Coupled Ocean Atmosphere Response Experiment (COARE) 2-day wave appears roughly similar to the one of Schumacher et al. (2008) (see their Fig. 8). Similar analysis based on the COARE MJO reveals weaker convergence (see their Fig. 15).

The short transition time scales and, hence, the importance of the underlying dynamical forcing are consistent with the results of recent studies. Over tropical Africa, this fits the observation that deep convection initiation seems often linked to surface or surfaceinduced features such as lakes, mountains, and vegetation breezes (Schroeder et al. 2009; Garcia-Carreras et al. 2010). Takayabu et al. (2010) investigated heating profiles obtained from TRMM and concluded that deep convective systems are strictly bounded by large-scale subsidence. Finally, the very recent study by Rapp et al. (2011)_using Global Precipitation Climatology Project (GPCP), 40-yr European Centre for Medium-Range Weather Forecasts (ECMWF) Re-Analysis (ERA-40), and TRMM data-indicated that positive low- and midlevel moisture anomalies precede deep convection. The analysis was, however, inconclusive concerning the origin of this moisture but did indicate that the amount of extra cloud water from shallow and congestus clouds available for evaporation prior to deep events fell short to explain the observed increase in moisture.

Despite emphasizing the role of vertical motions, the present analysis does not make any specific statement about the nature of such motions. Ascent (or convergence) may be achieved through various mechanisms, as noted in section $2 \mathrm{c}$. Nor does the analysis resolve the outstanding and well-known issue that convergence is likely both a cause and consequence of convective heating.

\section{Conclusions}

The present study investigated the transition to deep convection, from the appearance of the first cumulus congestus to the first cumulonimbus, and aimed at assessing its underlying mechanisms. Focus was set on the potential role of cumulus congestus in moistening the atmosphere and thus preconditioning it for deep convection. Two views were contrasted. In the first view, cumuli congestus are assumed to locally moisten the atmospheric column. The moistening is directly related to the rate of surface evaporation, which, in an atmosphere whose large-scale motion field is quiescent, sets the rate at which congestus clouds can detrain their moisture into the environment. When the column is sufficiently moist, deep convective cells develop. In the second view, deep convection is triggered because of some form of imposed ascent. Vertical motion may be induced by large-scale disturbances, waves, mesoscale circulations, cold pools, etc. The vertical column primarily moistens as a result of moisture convergence. 
Using a time-scale analysis based upon ship observations, large-eddy simulations, and brightness temperature measurements, it was found that if midtropospheric moisture availability is assumed to be a limiting factor in the development of convection, congestus moistening of the midtroposphere proceeds too slowly to explain the rapid transition to deep convection that is observed and simulated in the tropics. This is especially true over regions frequently experiencing developing cumulonimbi, whose initiation pattern corroborates the above-mentioned second view. Although, taken separately, individual lines of argument presented in this study can always be subject to criticism, the preponderance of evidence is difficult to reconcile with the idea that congestus moistening is important to the local initiation of deep convection. This evidence comprises the following:

- Very fast observed transition time scales, on the order of a couple of hours between congestus and cumulonimbus. The latter time scales are shorter than any of the estimates of the time needed by congestus clouds to bring the atmosphere into a moist enough state to support deep convection (see Table 1).

- A faster transition over land than over ocean.

- A majority of cumulus congestus $(60 \%)$, which never transitions to deep convection.

- A probability of congestus clouds growing into cumulonimbus, which does not increase with increasing congestus lifetime.

- The fact that the presence of cumulus congestus over a region does not enhance the likelihood for future deep convection initiation for lead times longer than $4 \mathrm{~h}$, as compared to clear-sky conditions.

- A transition time that increases with increasing horizontal scale of the convective systems.

The results are consistent with the observation that even rather weak vertical motion field, which is at least present over the Atlantic, can moisten the midtroposphere much more efficiently than congestus clouds. The results also indicate that moisture convergence (second view) is more important than surface fluxes (first view) for the development of deep convection.

Indubitably, cumulus congestus is an important cloud category per se. They shape the climate of the tropics because of their frequent occurrence and rain production. However, they are not viewed as determinant for the initiation of deep convection because they are unable to locally enhance its likelihood.

Acknowledgments. The study was supported by the Max Planck Society for the advancement of science. Use of GATE data and of the supercomputer facilities at the Deutsches Klimarechenzentrum (DKRZ) is

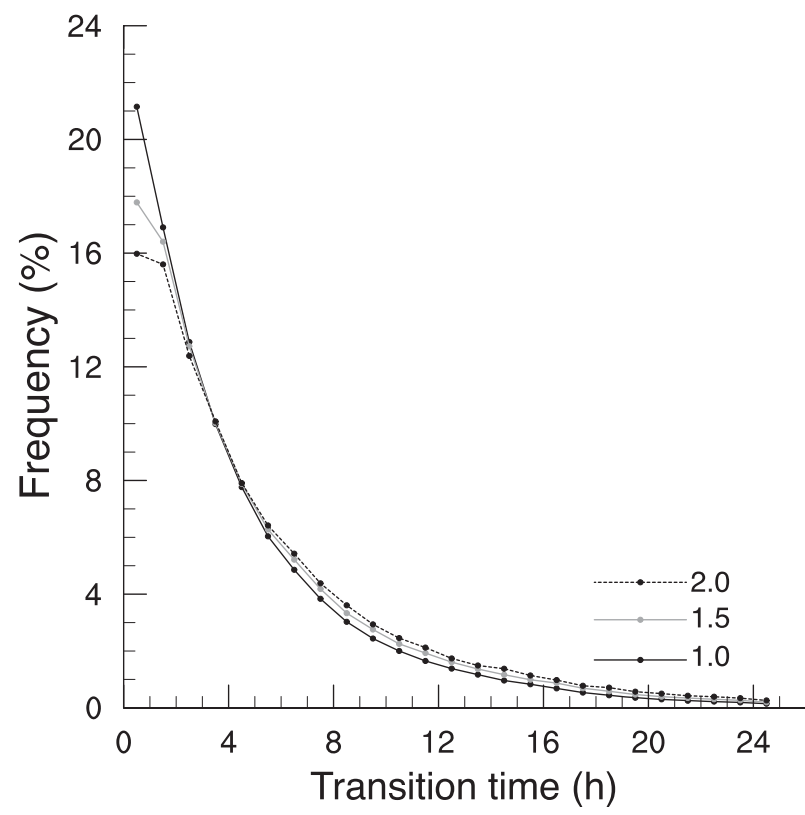

FIG. 10. Frequency distribution (\%) of $\tau_{*}(\mathrm{~h})$ sampled over the full domain for boxes of $1^{\circ} \times 1^{\circ}$ (black, identical to gray curve in Fig. $6 a$ ), $1.5^{\circ} \times 1.5^{\circ}$ (gray), and $2^{\circ} \times 2^{\circ}$ (dashed black) resolution. Only transient congestus events are included.

acknowledged. The authors thank Louise Nuijens for helpful comments on this manuscript and Christian Jakob for discussion. Insightful comments of the reviewers, which helped improve this manuscript and the presented arguments, are acknowledged.

\section{APPENDIX}

\section{Sensitivity Analysis}

The estimation of $\tau_{*}$ involves a number of subjective choices, as noted in section $2 \mathrm{c}$. The sensitivity of the results to these choices is examined in this appendix.

Modifying the brightness temperature thresholds or the other requirements on cloud number and cloud lifetime impacts the time-scale estimates. For instance, brightness temperature thresholds of 280 and $220 \mathrm{~K}$ in place of 273 and $240 \mathrm{~K}$, respectively, prolong $\tau_{*}$. The observed values increase to about $7 \mathrm{~h}$ over land and $10 \mathrm{~h}$ over ocean. Likewise, $\tau_{*}$ increases to $15 \mathrm{~h}$ in $\mathrm{W} 0,10 \mathrm{~h}$ in $\mathrm{W} 1 \mathrm{q}, 6 \mathrm{~h}$ in W1, and $2 \mathrm{~h}$ in W5. Comparison of these values again reveals that the observed transition time scales are faster than the time scale of cumulus congestus moistening. Hence, the bulk of our conclusions remains unchanged.

The adopted Eulerian perspective may be of more concern. Both congestus and deep clouds can be advected into and out of the specified $1^{\circ} \times 1^{\circ}$ boxes, with the potential to falsify our results. Figure 8 already indicated 
that the convective systems tend to be stationary in their early development stage, which minimizes possible contamination by advection. As a further test, $\tau_{*}$ is recomputed using different box sizes. Figure 10 is analogous to Fig. 6a, whereby the lines represent the different box sizes. The other criteria used in the detection algorithm stay as previously. Comparison of the different curves reveals a very good agreement. The derived frequency distributions do not vary much with box sizes, thus excluding a strong contamination of the results by advection issues. As final test, $\tau_{*}$ is determined for a subset of events, which are defined as follows. The existence of four conjoint grid points with brightness temperature below $240 \mathrm{~K}$ and no other deep activity in a radius of $50 \mathrm{~km}$ is requested. This marks the start of the deep phase. For each of these events, the start of the congestus phase is determined by going backward in time until all the grid points in a search radius of $50 \mathrm{~km}$ exhibit temperatures above $273 \mathrm{~K}$. The ensuing $\tau_{*}$ distribution is akin to the distributions in Figs. 6 and 10, albeit the total number of events is strongly reduced. Visual inspection of the spatial and temporal evolution of the congestus and deep cloud fields also supports the derived time scales.

\section{REFERENCES}

Ackerman, A. S., and Coauthors, 2009: Large-eddy simulations of a drizzling, stratocumulus-topped marine boundary layer. Mon. Wea. Rev., 137, 1083-1110.

Back, L. E., and C. S. Bretherton, 2005: The relationship between wind speed and precipitation in the Pacific ITCZ. J. Climate, 18, 4317-4328.

Benedict, J. J., and D. A. Randall, 2007: Observed characteristics of the MJO relative to maximum rainfall. J. Atmos. Sci., 64, 2332-2354.

Blade, I., and D. L. Hartmann, 1993: Tropical intraseasonal oscillations in a simple nonlinear model. J. Atmos. Sci., 50, 2922 2939.

Bretherton, C. S., M. E. Peters, and L. E. Back, 2004: Relationships between water vapor path and precipitation over the tropical oceans. J. Climate, 17, 1517-1528.

Brown, A., and Coauthors, 2002: Large-eddy simulation of the diurnal cycle of shallow cumulus convection over land. Quart. J. Roy. Meteor. Soc., 128, 1075-1093.

Brown, R., and C. Zhang, 1997: Variability of midtropospheric moisture and its effect on cloud-top height distribution during TOGA COARE. J. Atmos. Sci., 54, 2760-2774.

Bryan, G. H., J. C. Wyngaard, and J. M. Fritsch, 2003: Resolution requirements for the simulation of deep moist convection. Mon. Wea. Rev., 131, 2394-2416.

Casey, S. P. F., A. E. Dessler, and C. Schumacher, 2009: Five-year climatology of midtroposphere dry air layers in warm tropical ocean regions as viewed by AIRS/Aqua. J. Appl. Meteor. Climatol., 48, 1831-1842.

Derbyshire, S. H., I. Beau, P. Bechtold, J. Y. Grandpeix, J. M. Piriou, J. L. Redelsperger, and P. M. M. Soares, 2004: Sensitivity of moist convection to environmental humidity. Quart. J. Roy. Meteor. Soc., 130, 3055-3079.
Garcia-Carreras, L., D. J. Parker, C. M. Taylor, C. E. Reeves, and J. G. Murphy, 2010: Impact of mesoscale vegetation heterogeneities on the dynamical and thermodynamic properties of the planetary boundary layer. J. Geophys. Res., 115, D03102, doi:10.1029/2009JD012811.

Haertel, P. T., G. N. Kiladis, A. Denno, and T. M. Rickenbach, 2008: Vertical-mode decompositions of 2-day waves and the Madden-Julian Oscillation. J. Atmos. Sci., 65, 813-833.

Hendon, H. H., and K. Woodberry, 1993: The diurnal cycle of tropical convection. J. Geophys. Res., 98 (D9), 16 623-16 637.

Holloway, C. E., and J. D. Neelin, 2009: Vertical structure, column water vapor, and tropical deep convection. J. Atmos. Sci., 66, $1665-1683$.

Houze, R. A., and C. P. Cheng, 1977: Radar characteristics of tropical convection observed during GATE: Mean properties and trends over the summer season. Mon. Wea. Rev., 105, 964-980.

— , and A. K. Betts, 1981: Convection in GATE. Rev. Geophys., 19, 541-576.

Jensen, M. P., and A. D. Del Genio, 2006: Factors limiting convective cloud-top height at the ARM Nauru Island climate research facility. J. Climate, 19, 2105-2117.

Johnson, R. C., T. M. Rickenbach, S. A. Rutledge, P. E. Ciesielski, and W. H. Schubert, 1999: Trimodal characteristics of tropical convection. J. Climate, 12, 2397-2418.

Jones, C., and B. C. Weare, 1996: The role of low-level moisture convergence and ocean latent heat fluxes in the Madden and Julian oscillation: An observational analysis using ISCCB data and ECMWF analyses. J. Climate, 9, 3086-3104.

Khairoutdinov, M., and D. Randall, 2006: High-resolution simulation of shallow-to-deep convection transition over land. J. Atmos. Sci., 63, 3421-3436.

— S. K. Krueger, C.-H. Moeng, P. A. Bogenschutz, and D. A. Randall, 2009: Large-eddy simulation of maritime deep tropical convection. J. Adv. Model. Earth Syst., 1 (15), 1-13.

Krueger, S., 1988: Numerical simulation of tropical cumulus clouds and their interaction with the subcloud layer.J. Atmos. Sci., 45, 2221-2250.

Kuang, Z., and C. S. Bretherton, 2006: A mass-flux scheme view of a high-resolution simulation of a transition from shallow to deep cumulus convection. J. Atmos. Sci., 63, 1895-1909.

Lau, K. M., and H. T. Wu, 2003: Warm rain processes over tropical oceans and climate implications. Geophys. Res. Lett., 30, 2290, doi:10.1029/2003GL018567.

Luo, Z., G. Y. Liu, G. L. Stephens, and R. H. Johnson, 2009: Terminal versus transient cumulus congestus: A CloudSat perspective. Geophys. Res. Lett., 36, L05808, doi:10.1029/ 2008 GL036927.

Machado, L., J. P. Duvel, and M. Desbois, 1993: Diurnal variations and modulation by easterly waves of the size distribution of convective cloud clusters over wet Africa and the Atlantic Ocean. Mon. Wea. Rev., 121, 37-49.

Mapes, B., and R. Houze, 1995: Diabatic divergence profiles in western Pacific mesoscale convective systems. J. Atmos. Sci., 52, 1807-1828.

— P. E. Ciesielsk, and R. H. Johnson, 2003: Sampling errors in rawinsonde-array budgets. J. Atmos. Sci., 60, 2697-2714.

Masunaga, H., 2012: A satellite study of the atmospheric forcing and response to moist convection over tropical and subtropical oceans. J. Atmos. Sci., 69, 150-167.

— precipitating clouds ranging from shallow to deep convective systems. Geophys. Res. Lett., 33, L16805, doi:10.1029/ 2006GL026547. 
— T. S. L'Ecuyer, and C. D. Kummerow, 2005: Variability in the characteristics of precipitation systems in the tropical Pacific. Part I: Spatial structure. J. Climate, 18, 823-840.

Parsons, D. B., K. Yoneyama, and J. L. Redelsperger, 2000: The evolution of the tropical western Pacific atmosphere-ocean system following the arrival of a dry intrusion. Quart. J. Roy. Meteor. Soc., 126, 517-548.

Petty, G. W., 1999: Prevalence of precipitation from warm-topped clouds over eastern Asia and the western Pacific. J. Climate, 12, 220-229.

Pielke, R., 2001: Influence of the spatial distribution of vegetation and soils on the prediction of cumulus convective rainfall. Rev. Geophys., 39, 151-177.

Rapp, A. D., C. D. Kummerow, and L. Fowler, 2011: Interactions between warm rain clouds and atmospheric preconditioning for deep convection in the tropics. J. Geophys. Res., 116, D23210, doi:10.1029/2011JD016143.

Raymond, D. J., G. B. Raga, C. S. Bretherton, J. Molinari, C. Lopez-Carrillo, and Z. Fuchs, 2003: Convective forcing in the intertropical convergence zone of the eastern Pacific. J. Atmos. Sci., 60, 2064-2082.

Redelsperger, J., D. Parsons, and F. Guichard, 2002: Recovery processes and factors limiting cloud-top height following the arrival of a dry intrusion observed during TOGA COARE. J. Atmos. Sci., 59, 2438-2457.

Schnetz, J., P. Pili, S. Tjemkes, D. Just, J. Kerkmann, S. Rota, and A. Ratier, 2002: An introduction to Meteosat Second Generation (MSG). Bull. Amer. Meteor. Soc., 83, 977-992.

Schroeder, M., M. Koenig, and J. Schmetz, 2009: Deep convection observed by the Spinning Enhanced Visible and Infrared Imager on board Meteosat 8: Spatial distribution and temporal evolution over Africa in summer and winter 2006. J. Geophys. Res., 114, D05109, doi:10.1029/2008JD010653.

Schumacher, C., M. H. Zhang, and P. E. Ciesielski, 2007: Heating structures of the TRMM field campaigns. J. Atmos. Sci., 64, 4289-4300

— P. E. Ciesielski, and M. H. Zhang, 2008: Tropical cloud heating profiles: Analysis from KWAJEX. Mon. Wea. Rev., 136, 2593-2610.

Seifert, A., and K. Beheng, 2006: A two-moment cloud microphysics parameterization for mixed-phase clouds. Part I: Model description. Meteor. Atmos. Phys., 92, 45-66.

Siebesma, A., and Coauthors, 2003: A large eddy simulation intercomparison study of shallow cumulus convection. J. Atmos. Sci., 60, 1201-1219.

Slingo, J., P. Inness, R. Neale, S. Woolnough, and G. Yang, 2003: Scale interactions on diurnal to seasonal timescales and their relevance to model systematic errors. Ann. Geophys., 46, 139155.

Stephens, G. L., and Coauthors, 2002: The CloudSat mission and the A-train: A new dimension of space-based observations of clouds and precipitation. Bull. Amer. Meteor. Soc., 83, 17711790.

Stevens, B., and Coauthors, 2005: Evaluation of large-eddy simulations via observations of nocturnal marine stratocumulus. Mon. Wea. Rev., 133, 1443-1462.

Takayabu, Y. N., J. Yokomori, and K. Yoneyama, 2006: A diagnostic study on interactions between atmospheric thermodynamic structure and cumulus convection over the tropical western Pacific Ocean and over the Indochina peninsula. J. Meteor. Soc. Japan, 84, 151-169.

_ S. Shige, W.-K. Tao, and N. Hirota, 2010: Shallow and deep latent heating modes over tropical oceans observed with TRMM spectral latent heating data. J. Climate, 23, 20302046.

Takemi, T., O. Hirayama, and C. Liu, 2004: Factors responsible for the vertical development of tropical oceanic cumulus convection. Geophys. Res. Lett., 31, L11109, doi:10.1029/ 2004GL020225.

Tompkins, A., 2001: Organization of tropical convection in low vertical wind shears: The role of water vapor. J. Atmos. Sci., $\mathbf{5 8}, 529-545$.

Waite, M. L., and B. Khouider, 2010: The deepening of tropical convection by congestus preconditioning. J. Atmos. Sci., 67, 2601-2615.

WMO, 1956: International Cloud Atlas. World Meteorological Organization, $155 \mathrm{pp}$.

Wu, C. H., B. Stevens, and A. Arakawa, 2009: What controls the transition from shallow to deep convection? J. Atmos. Sci., 66, 1575-1590.

Xu, K., A. Arakawa, and S. Krueger, 1992: The macroscopic behavior of cumulus ensembles simulated by a cumulus ensemble model. J. Atmos. Sci., 49, 2402-2420.

Yu, L., J. Xiangze, and R. A. Weller, 2008: Multidecade global flux datasets from the Objectively Analyzed Air-Sea Fluxes (OAFlux) project: Latent and sensible heat fluxes, ocean evaporation, and related surface meteorological variables. Woods Hole Oceanographic Institution OAFlux Project Tech. Rep. OA-2008-01, 64 pp.

Yuter, S., R. Houze, E. Smith, T. Wilheit, and E. Zipser, 2005: Physical characterization of tropical oceanic convection observed in KWAJEX. J. Appl. Meteor., 44, 385-415.

Zhang, C., 2005: Madden-Julian Oscillation. Rev. Geophys., 43, RG2003, doi:10.1029/2004RG000158. 